\title{
Mutual Determination between Clausal Constituents
}

\author{
Qingshun $\mathrm{He}^{1, *}$ \& Meiling $\mathrm{Fu}^{1}$ \\ ${ }^{1}$ Faculty of English Language and Culture, Guangdong University of Foreign Studies, Guangzhou, China \\ *Corresponding author: Faculty of English Language and Culture, Guangdong University of Foreign Studies, \\ Guangzhou, China. Tel: 86-158-0002-9026. E-mail: markman1998@163.com
}

Received: November 8, 2014 Accepted: January 9, 2015 Online Published: January 21, 2015

doi:10.5430/wjel.v5n1p14 URL: http://dx.doi.org/10.5430/wjel.v5n1p14

\begin{abstract}
In formal syntactic analysis, the noun phrase functioning as subject governs the verb phrase functioning as predicate, and the verb within the verb phrase in turn governs the noun phrase functioning as its object. Similarly, in Systemic Functional Linguistics, the central element of a clause is the verbal group; it determines the nominal group functioning as its participant. However, neither formal nor functional syntactic analysis can tell the difference between the two sentences Mary has become a good person and Mary has become a dead person. Following the basic ideas of stratum, metafunction, cline and rank in Systemic Functional Linguistics, this research analyzes the functional syntactic structures of the two sentences from the ideational and interpersonal perspectives, proposing that although it is the verbal group that determines the nominal group functioning as its object in a clause, the nominal group itself has a reflexive effect on the verbal group. That is, the constituents in a clause are mutually determined.
\end{abstract}

Keywords: mutual determination; syntactic analysis; systemic functional linguistics

\section{Introduction}

Ever since Chomsky (1957) published his Syntactic Structures, the two sentences in (1) and (2) have long been discussed under the framework of Generative Linguistics. They are always taken as an evidence for the assumption that children are born with some innate language competence.

(1) Mary is easy to please.

(2) Mary is eager to please.

Although the two sentences are exactly the same in syntactic structure, they are quite different in meaning. Mary in (1) is the logic object of the verb please (meaning "someone pleases Mary"), while in (2) Mary is the logic subject of the verb please (meaning "Mary pleases someone else"). Structural linguistics cannot distinguish (1) from (2) through Immediate Constituent Analysis. In Chomsky's $(1957 ; 1965)$ thinking, any sentence can be analyzed in its surface structure and deep structure. Although the two sentences are the same in surface structure, they are different in deep structure. In (1), Mary is the surface subject of is easy to please and the deep object of please. Hence, (1) can be rewritten as (1a) and (1b):

(1) a. To please Mary is easy.

b. It is easy to please Mary.

In (2), Mary is still the surface subject of is eager to please; it is also the deep subject of please, hence cannot be analyzed as (1). To make it clear, the tree diagrams of (1) and (2) are shown as Figures 1 and 2 respectively: 


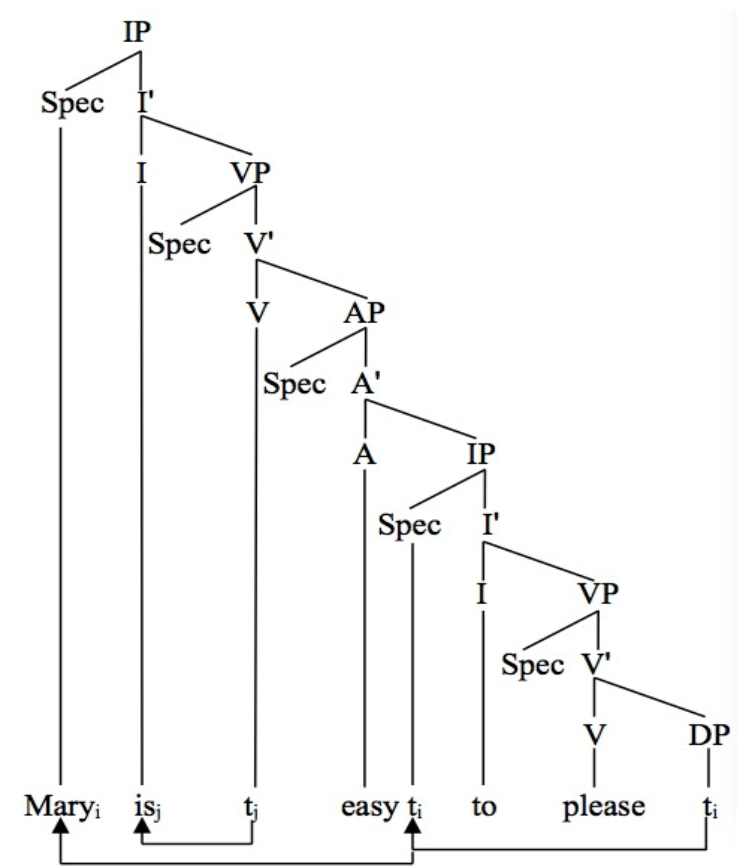

Figure 1. Syntactic Analysis of Mary is easy to please

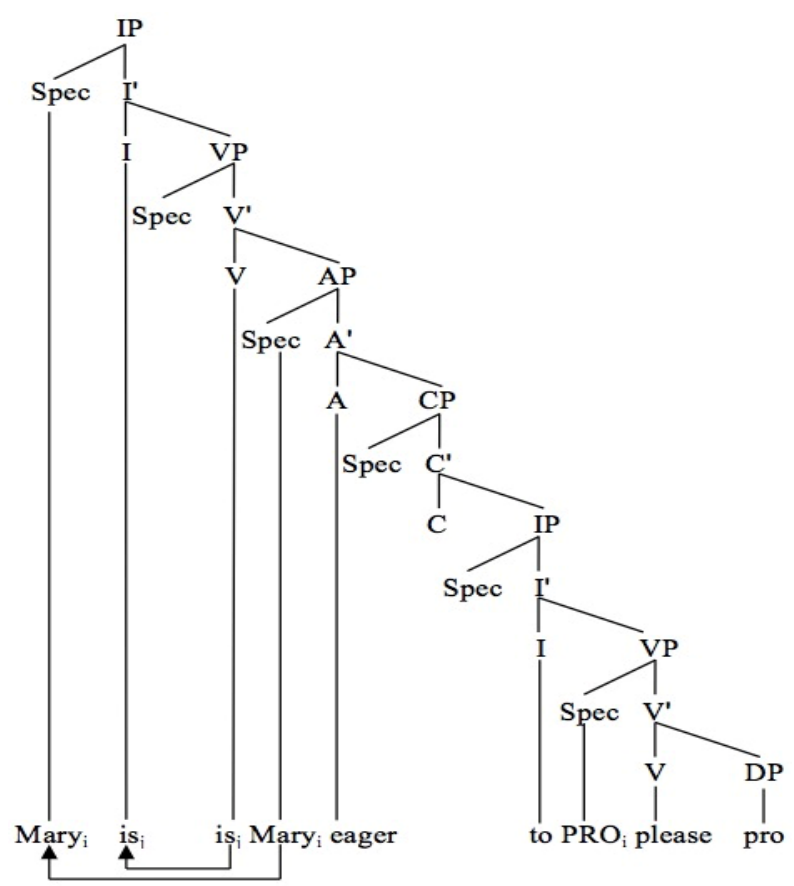

Figure 2. Syntactic Analysis of Mary is eager to please

Nevertheless, formal syntax cannot distinguish (3) from (4) in either surface structure or deep structure.

(3) Mary has become a good person.

(4) Mary has become a dead person. 


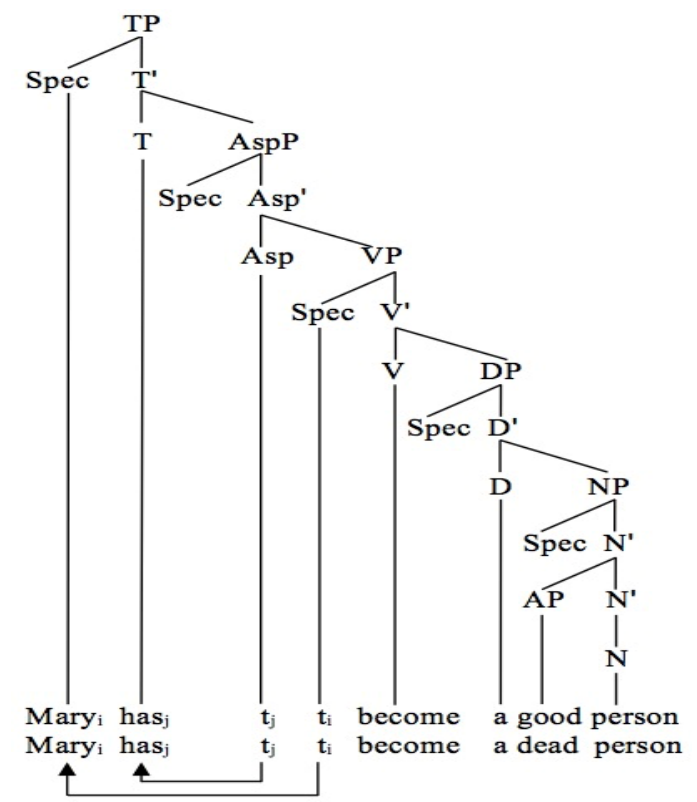

Figure 3. Syntactic Analysis of Mary has become a good/dead person

The two sentences in (3) and (4) are the same in both surface structure and deep structure. However, native speakers can still sense the difference between the two sentences by intuition. For example, we can tell that (5) is acceptable and (6) unacceptable:

(5) Mary has gradually become a good person.

(6) *Mary has gradually become a dead person.

The difference between (3) and (4) is in meaning. To analyze the syntactic structures of these two sentences, it is necessary to resort to semantic analysis. Systemic Functional Linguistics (SFL) developed by Halliday (1985; 1994) and Halliday \& Matthiessen $(2004 ; 2014)$ is meaning based. Therefore, in this paper, we will carry out an analysis of the syntactic structures of (3) and (4) in the framework of SFL. In section 2, we will introduce some basic ideas of SFL that are helpful for the analysis of functional syntax. In section 3, we will conduct the analysis from the perspective of metafunctions based on the relevant basic ideas of SFL.

\section{Approaching Functional Syntax}

SFL is different from TGL (Transformative and Generative Linguistics) in that it focuses on the differences between individual languages and their variations rather than the general principles of language. There are six basic ideas in SFL, i.e., metafunction, system, stratum, function, context and probability. SFL also characterizes itself in the notion of cline to deal with complicated language facts and hence introduces the concepts of rank and delicacy. Of the basic ideas and concepts, stratum, metafunction, cline and rank are closely related to this paper. They make the theoretical framework for this research.

\subsection{Language as a Multi-Stratal System}

Halliday $(1978$; 1979) considers language as a semiotic system. In contradistinction to formal linguistics which is semantically arbitrary, SFL is semantically natural. In SFL, every category is "based on meaning: it has a semantic as well as a formal, lexico-grammatical reactance" (Halliday \& Matthiessen, 1999, p. 4). This means that many grammatical categories are cryptotypic in Whorf's (1956) terms. It is because of the semantic naturalness that the semantic potential may have various representations at the lower level organization. Following the notion of "content plane" of language proposed by Hjelmslev (1943), Halliday \& Matthiessen (1999) divide language into the stratum of content and that of expression. The former is further divided into the semantic stratum and the lexico-grammatical stratum, and the latter includes phonology and graphology. The relationship between these three strata of language is realization, i.e., semantics is realized by lexico-grammar, and lexico-grammar is realized by phonology or graphology. See Figure 4: 


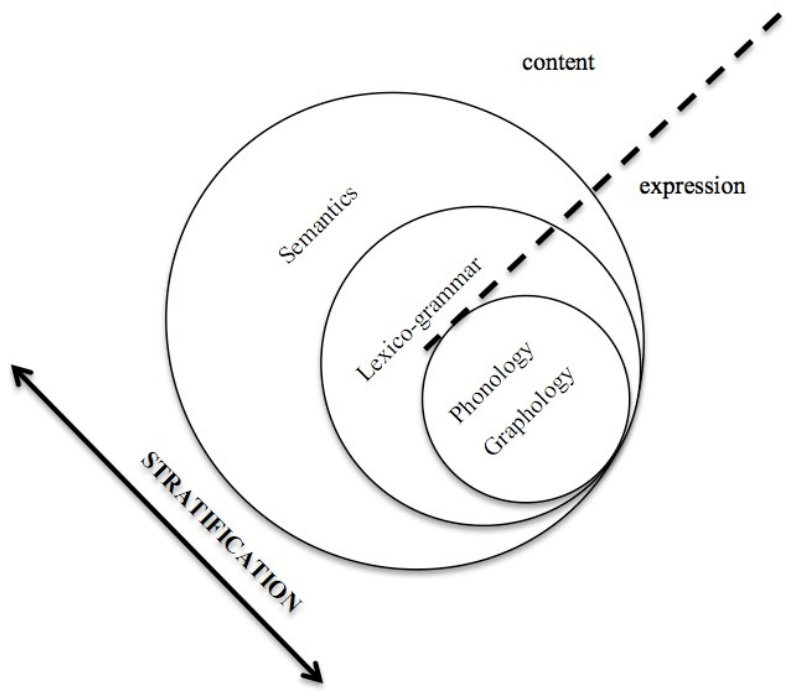

Figure 4. Three Strata System of Language

SFL studies language-in-use. The choice of meaning (semantic stratum) is realized as that of form (lexico-grammatical stratum). In theory, the realization process is that of free variation. A certain meaning can be realized by different forms, or vice versa. In (1) and (2), for example, the same grammatical structure realizes different semantic contents.

The idea of strata has important implications to the analysis of language. Take the stratum of lexico-grammar as an example. This stratum consists of two categories, i.e., lexis and grammar, which form a cline in delicacy. Generally, "the move in delicacy in the ideation base from 'most general' to 'most delicate' is construed lexico-grammatically as the move from 'grammar' to 'lexis'” (Halliday \& Matthiessen, 1999, p. 87).

Since there is no difference between (3) and (4) at the grammar end, then the difference must be manifested at the end of lexis. From this perspective, we can say that the ungrammaticality of (6) is resulted from no other thing than the adjective dead: there must be some difference between dead in (6) and good in (5).

\subsection{Cline}

What is closely related to the language strata is the notion of cline. As it is mentioned above, the move from grammar to lexis is a cline at the lexico-grammatical stratum. The notion of cline plays an important part in the study of SFL. Cline refers to those language units which cannot be included in any language category (Halliday \& Matthiessen, 1999). To better understand the notion of cline, it is necessary to introduce the concept of categorization. Simply speaking, "to categorize linguistically is to put together the linguistic symbols and the human experiences these symbols represent so as to set up categories" (Yang, 2007). The concept of categorization originates from the ancient Aristotelian Classical philosophy, according to which categories are defined in terms of sufficient and necessary features and all members in a category are equal in status. Influenced on by Wittgenstein's thinking on family resemblance, cognitive science has raised the prototype theory of semantic categorization, according to which there are degrees of membership based on the degrees of similarity. SFL is not oriented towards philosophy or logic; rather it is oriented towards language and language use. It concerns with "how meaning is construed in naturally occurring text" (Halliday \& Matthiessen, 1999, p. 72).

According to SFL, there are no clear boundaries between categories, and the members of two categories form a cline. For example, "the distinction between closed system patterns and open set patterns in language is in fact a cline" (Halliday, 1961 [2002]), and that between participants and circumstances is also a cline (Halliday \& Matthiessen, 1999). It can be said that the notion of categorization in cognitive science and that of cline in SFL are to some extent the same thing, the only difference being that the former emphasizes the experience of people and the latter, the language performance. The cline from grammar to lexis discussed in section 2.1 can be shown in Figure 5 (Halliday \& Matthiessen, 2014, p. 64):

lexico-grammar

(stratum of wording)

grammar

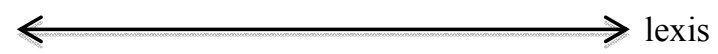


(closed systems, general

in meaning; structure) (open sets, specific in

meaning; collocation)

Figure 5. The Lexico-grammar Cline

The notion of cline is a major indicator in distinguishing SFL from formal grammars. It is helpful to explain many linguistic phenomena that formal grammars have difficulty explaining. Take (7) as an example:

(7) a. I worked for a local firm at that time, selling office equipment.

b. Alice walked on in silence, puzzling over the idea.

c. She met some people just leaving the building.

In (7), we can find a cline in the logico-semantic relations realized by non-finite clauses. In ( $7 \mathrm{a})$, the non-finite clause selling office equipment construes a logico-semantic relation of hypotactic elaboration. The non-finite clause leaving the building in $(7 \mathrm{c})$ is embedded, functioning as the post-modifier of the nominal group some people. However, in (7b), the relationship between the non-finite clause puzzling over the idea and the finite clause Alice walked on in silence is fuzzy: it lies in between hypotactic elaboration and embedding. If it is considered as elaboration, the whole construction is a clause complex, and if it is considered as embedding, the whole construction is a simple clause.

In the above section, we find that the difference between (3) and (4) is at the lexis end along the move from grammar to lexis at the stratum of lexico-grammar. The difference between good in (3) and dead in (4) under the notion of cline is that good is gradable and dead is not. For example, we can say very good but we cannot say very dead. This also explains why (6) is unacceptable.

\subsection{Metafunction}

In language analysis, we will consider not only the multi-strata of language and their realization but also the multi-functions of language. In Halliday's (1985; 1994) thinking, language assumes different functions in people's daily life. We can describe all the events in the internal and external world with language, and the participants and circumstances related to the events. We can also communicate with people and enact social processes with language. We can enable the realization of such different functions with relevant organizations of language. From this perspective and influenced on by Malinowski (1923; 1935) and Bühler (1933), Halliday (1970) categorizes all functions of language into three metafunctions: ideational, interpersonal and textual. These three metafunctions are closely intertwined to be realized as a clause. Therefore, the functional syntactic analysis of a clause can be carried out from the ideational, interpersonal and textual perspectives. Transitivity, Mood and Theme can be taken as three major syntactic choices in an English clause (Halliday, 1968, p. 207). This is the syntactic basis for language functions. Later, Halliday (1978) includes functions of language into the stratum of semantics, considering functions as modes of meaning and divides ideational metafunction into experiential and logical metafunctions. Halliday (1970; $1978 ; 1979 ; 1985 ; 1994)$ and Halliday \& Matthiessen $(1999 ; 2004 ; 2014)$ have offered us a full picture of the idea of metafunction in SFL.

Take (1) and (2) as examples. Huang (2010) analyzes their functional syntactic structures from the ideational and interpersonal metafunctions. Ideationally, the two clauses are of different types of process, i.e., (1) relational and (2) mental.

\begin{tabular}{llll}
\hline (1) & Mary & is & easy to please. \\
& Carrier & Process: Relational & Attribute \\
\hline (2) & Mary & is eager & to please. \\
& Senser, Phenomenon & Process: Mental & Process: Mental \\
\hline
\end{tabular}

The type of process determines the function of participants. For example, Mary in (1) is the Carrier of the relational process is, and in (2), the Senser of the mental process is eager and the Phenomenon of the mental process please.

Interpersonally, the adjective easy is an assessment of the situation (process) to please Mary, while the adjective eager is a description of the status of a conscious being. The reason why (8) is acceptable but (9) is not is that the adjectives in (8) can all be used to evaluate a situation (Huang, 2010):

(8) a. To please Mary is easy/difficult/tough/hard.

b. It is easy/difficult/tough/hard to please Mary.

(9) a. *To please Mary is eager/happy/afraid/nervous.

b. *It is eager/happy/afraid/nervous to please Mary. 
However, we can say (10), but not (11) because the adjectives in (11) cannot be used to describe the feeling of conscious beings.

(10) Mary is eager/happy/afraid/nervous to please everyone here.

(11) * Mary is easy/difficult/tough/hard tołlease everyone here.

We can see that in formal analysis, (1) and (2) are of the same surface structure but of different deep structures, while in functional analysis, they are different in both transitivity and mood structures.

\subsection{Ranked Constituent Analysis}

Like structuralist linguistics, SFL concerns with the form and function of language in syntax analysis. Formal syntactic analysis is grammar oriented; it takes a maximal bracketing approach, i.e., Immediate Constituent Analysis, concerning mainly about what meaning or meanings a form can express. The relationship between the two phrases at each level is emphasized. According to this analysis, the constituent on the left governs that on the right (Haegeman, 1994, p. 134). That is, in a clause, the noun phrase functioning as the subject governs the verb phrase, and in the verb phrase, the verb governs the noun phrase functioning as the object of the verb. This means that it is the verb that determines the type of the nominal phrase that follows it. For example, the noun phrase following the verb kill must be animate, and that following the verb deserve must be deverbal.

Functional syntactic analysis takes a minimal bracketing approach, i.e., Ranked Constituent Analysis, concerning mainly about what forms can realize a certain meaning. According to this analysis, the central element of a clause is the verbal group. It determines the types of nominal groups functioning as its participants. For example, a mental process requires its Senser to be a conscious being. In ranked constituent analysis, there are two principles based on which we can label the constituents of the grammatical structure: one being to assign a class to a constituent, and the other, to assign a function to it. For example, (3) and (4) can be diagrammed as Figures 6 and 7 following these two principles of labeling:

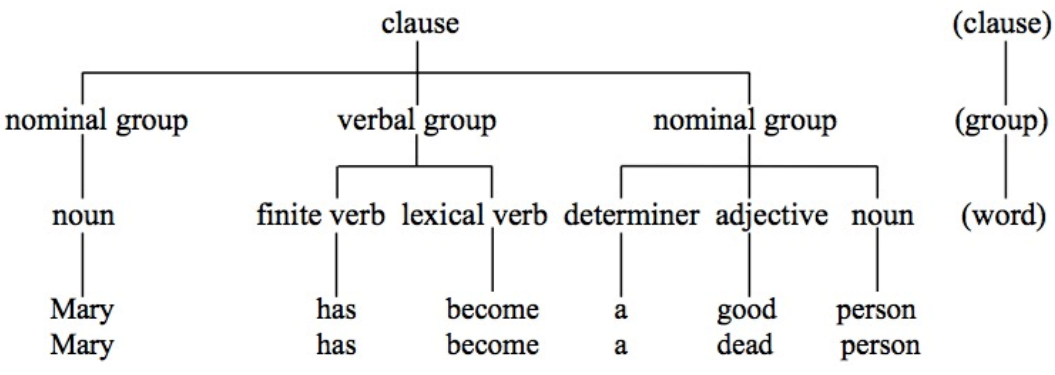

Figure 6. Class Labeling of Ranked Constituent Analysis

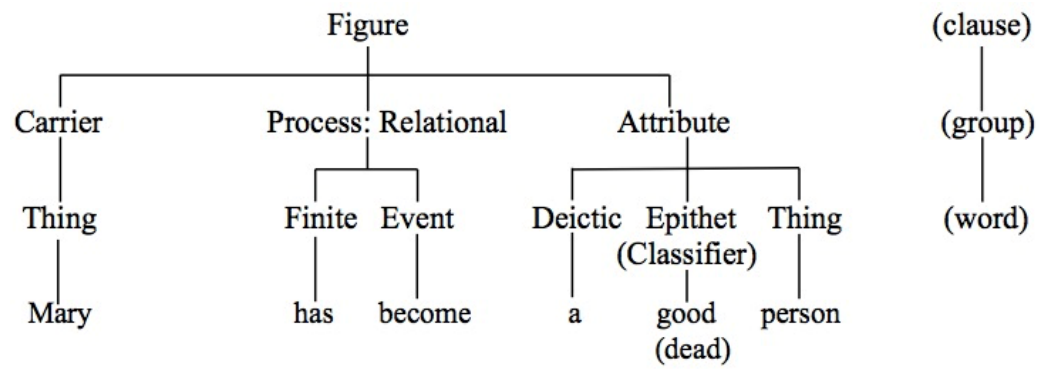

Figure 7. Function Labeling of Ranked Constituent Analysis

Although (3) and (4) are of the same syntactic structure and semantic structure, (5) and (6) are obviously different. The only difference between (3) and (4) is in the adjectives that define the nominal phrases, i.e., good and dead respectively. At the lexico-grammatical stratum, clause is the highest rank, and morpheme, the lowest, with phrase/group and word lying in between. At the clause rank, (3) and (4) are of the same structure as well as that of (1) and (2). The difference between good and dead is at the word rank because they both function within a nominal group. 


\section{Functional Syntactic Analysis}

Traditional grammar constitutes one set of syntactic structure, while functional grammar, three sets of syntactic structure. For example, the syntactic structures of the clause shortages made life difficult can be shown in Figure 8:

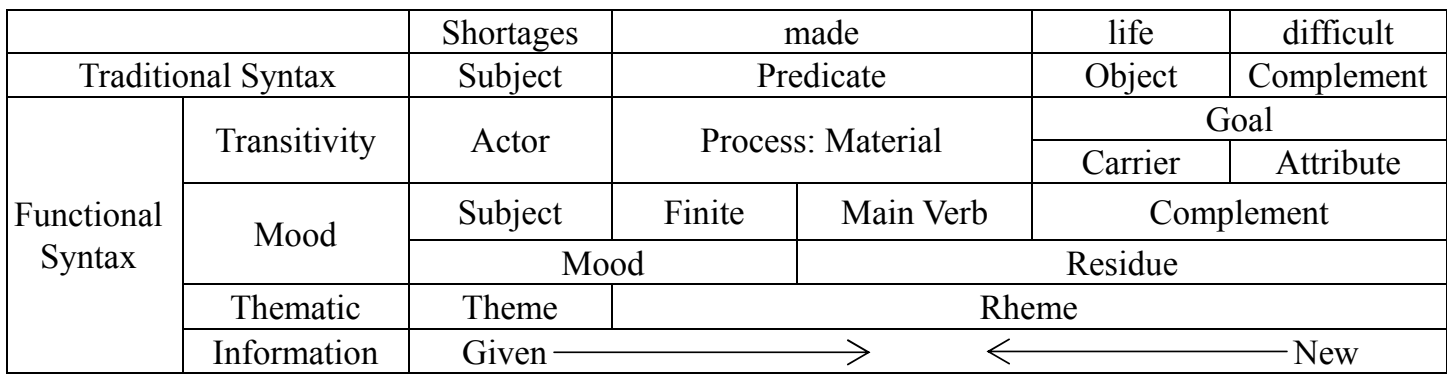

Figure 8. Traditional and Functional Structures

In this section, we will discuss the functional structures of (3) and (4) based on the above mentioned basic ideas and concepts of SFL from the perspectives of ideational and interpersonal metafunctions.

\subsection{Ideational Analysis}

The multi-stratal analysis of language shows that although (1) and (2) are the same in form, they may have different meanings. In other words, they are the formal realization of different meanings. The same formal structure does not mean at all that they are the same or similar in meaning. The meaning of a clause is determined at the semantic stratum rather than at the lexico-grammatical stratum (Huang, 2010). Therefore, (1) and (2) are of different types of process. However, the process of (3) and that of (4) are both relational.

\begin{tabular}{llll}
\hline (3) & Mary & has become & a good person. \\
(4) & Mary & has become & a dead person. \\
\hline & Carrier & Process: Relational & Attribute \\
\hline
\end{tabular}

It is the adverb gradually that makes (6) unacceptable. This is because gradually always collocates with durational verbs. This means that become in (5) is a durational verb and that in (6) a transient verb. However, this is not necessarily true. A verb can be either transitive or intransitive in different contexts, but it can never be both transitive and intransitive in the same context. This is also true for durational or transient verbs. Then what makes (6) unacceptable?

When discussing the experiential structures of nominal groups, Halliday \& Matthiessen (2014, p. 364-386) distinguish four types of functional elements characterizing the Thing in question: Deictic, Numerative, Epithet and Classifier. Epithets can further be divided into experiential Epithets, construing the experience of the entity that it represents, and interpersonal Epithets, expressing the speaker's subjective attitude towards it. These functional elements are fixed in order, and "interpersonal Epithets tend to precede the experiential ones" (Halliday \& Matthiessen, 2014, p. 377). The major difference between experiential Epithets and interpersonal epithets is that the former are potentially defining, and the latter are not. They contribute to appraisal in the sense of Martin \& White (2005) and hence are negotiable, that is, they tend to be modified by degree adverbs. See examples (12), (13) and (14) (These examples are quoted from Halliday \& Matthiessen, 2014, p. 376):

(12) New numbers also will be inserted between the new area code and the old phone number. (experiential Epithet)

(13) I knocked on the door and an awfully sweet lady came. (interpersonal Epithet)

(14) Then he saw it - a large red feather barely sticking out of the straw mat. (interpersonal Epithet + experiential Epithet)

The Classifier indicates a particular subclass of Thing. The line between Epithet and Classifier is not clear. The major difference between Epithet and Classifier is that the latter does not accept degrees of comparison or intensity; "they tend to be organized in mutually exclusive and exhaustive sets" (Halliday \& Matthiessen, 2014, p. 377). It is a cline from interpersonal Epithets through experiential Epithets to Classifiers.

In (3) good functions as an interpersonal Epithet and in (4) dead can be taken as a Classifier. Therefore, we can have (15) rather than (16):

(15) Mary has become a very good person. 
(16) *Mary has become a very dead person.

Through this analysis, it can be concluded that although the type of noun phrase is generally governed by the verb in formal syntax, the noun phrase has a reflexive effect on the verb; it also determines the type of verb that governs it.

\subsection{Interpersonal Analysis}

The interpersonal analysis can be carried out from two perspectives, i.e., the expression of appraisal and the realization of mood. As for the difference between (3) and (4), we will only discuss appraisal.

Grammatically, the adjective good in (3) describes the property of the noun person, but interpersonally it is an assessment of the process. In (4), dead describes the status of the noun person; it is not an assessment of some process. In this sense, we can say (17), but not (18):

(17) Mary has become better.

(18) * Mary has become deader.

Therefore, better in (17) functions not only as the attribute of Mary in transitivity analysis but also as an assessment of the verbal group has become in interpersonal analysis, while deader in (18) is grammatically unacceptable. This is because dead is not gradable and can function only as the attribute of Mary; it has no interpersonal meaning. This does not mean that adjectives functioning as experiential Epithet have not at all a interpersonal meaning. In fact, "there is no hard and fast line between these two" (Halliday \& Matthiessen, 2014, p. 376).

\subsection{Mutual Determination}

Human experiences can be represented as four domains of "goings-on": doing (including happening), sensing, saying and being (including having) (Halliday $(1985 ; 1994)$. These four domains of goings-on can be divided into the experience of the inner world and that of the external world. The grammatical categories are those of material process and mental process. In addition, the relationship between one fragment of experience and the other can be recognized as a third type of process, the relational process. At the boundaries along the cline, there are three minor processes: behavioural process, verbal process and existential process. These six processes are not isolated from each other; they form a cline.

The verb $d o$ can be taken as one typical member in the category of material process and be the typical member in the category of relational process. The cline from relational process to material process is that from a verbal group of state to a verbal group of action. Although become is also a relational verb, it is different from be in that the former has the feature of "doing" and "happening" and the latter has the feature of the status of existence. That is to say that become lies in between the typical member do of the material process and the typical member be of the relational process. On the other hand, it does not stay static along the cline; it vibrates between the two poles. It is now the nominal group that follows that determines towards which pole it vibrates. Even the typical member be in the category of relational process will be affected by the type of attribute. In He is good and He is dead for example, is in the former is more active than that in the latter because good is an interpersonal attribute and the dead, an experiential attribute. A further typical example is the verb get. See (19) and (20):

(19) a. He is better.

b. He gets better.

(20) a. *He is being better.

b. He is getting better.

An adverb functions to modify the verb and it is the adverb gradually that makes (6) unacceptable, hence the two becomes in (3) and (4) are different in meaning. The only element responsible for the difference is in the two adjectives, i.e., good and dead. In this sense, the nominal group functioning as the object of the verbal group has a feedback effect on the verbal group. In this sense, the verbal group and the nominal group that functions as its object are mutually determined.

\section{Conclusion}

In formal grammar, it is popularly accepted that the noun phrase functioning as subject governs the verb phrase, and the verb in the verb phrase in turn governs the noun phrase functioning as its object. In SFL, the central element of a clause is the verbal group; it determines the status of the clause. Nominal groups function as participants of verbal groups. The type of a nominal group is determined by the type of the verbal group. However, research shows that 
nominal groups have a reflexive effect on verbal groups: they will exert some influence on verbal groups. Adverbial groups functioning as circumstances in a clause are related to verbal groups; they modify verbal groups or the whole clauses. When the same adverbial group modifying the same verbal group is grammatical in one context but not in another, it is the verbal group that is characterized with different semantic features. In a word, the constituents in a clause are mutually determined.

\section{References}

Bühler, K. (1934). Sprachtheorie: Die Darstellungfunktion der Sprache. Jena: G. Fischer.

Chomsky, N. (1957). Syntactic Structures. The Hague: Mouton.

Chomsky, N. (1965). Aspects of the Theory of Syntax. Cambridge, MA: The MIT Press.

Chomsky, N. (1981). Lectures on Government and Binding. Dordrecht: Foris.

Haegeman, L. (1994). Introduction to Government and Binding Theory $\left(2^{\text {nd }}\right.$ edition). Oxford: Blackwell.

Halliday, M. A. K. (1961[2002]). Categories of the theory of grammar. In J. Webster (Ed.), Collected Works of M. A. K. Halliday, vol. 1: On Grammar (pp. 37-94). London: Continuum.

Halliday, M. A. K. (1968). Notes on Transitivity and Theme in English. Part 3. Journal of Linguistics 4, 179-215.\# http://dx.doi.org/10.1017/S0022226700001882

Halliday, M. A. K. (1970/2002). Language structure and language function. In J. Webster (Ed.), Collected Works of M. A. K. Halliday, vol. 1: On Grammar (pp. 173-195). London: Continuum.

Halliday, M. A. K. (1978). Language as Social Semiotic: the Social Interpretation of Language and Meaning. London: Edward Arnold.

Halliday, M. A. K. (1979). Modes of meaning and modes of expression: types of grammatical structure, and their determination by different semantic functions. In D. J. Allerton, E. Carney \& D. Holdcroft (Eds.), Functions and Context in Linguistics Analysis (pp. 57-79). Cambridge: Cambridge University Press.

Halliday, M. A. K. (1985). An Introduction to Functional Grammar. London: Edward Arnold.

Halliday, M. A. K. (1994). An Introduction to Functional Grammar (2nd edition). London: Edward Arnold.

Halliday, M. A. K., \& Matthiessen, C. M. I. M. (2004). An Introduction to Functional Grammar (3rd edition). London: Edward Arnold.

Halliday, M. A. K., \& Matthiessen, C. M. I. M. (2014). Halliday's Introduction to Functional Grammar (4th edition). London \& New York: Routledge.

Huang, G.-W. (2010). A systemic functional analysis of "Mary is easy/eager to please". Foreign Language Teaching and Research, 42(4), 261-267.

Malinowski, B. (1923). The problem of meaning in primitive languages. In C. K. Ogden \& I. A. Richards (Eds.), The Meaning of Meaning (pp. 451-510). London: Routlege and Kegan Paul.

Malinowski, B. (1935). The Language of Magic and Garden, vol. 2, Coral Gardens and Their Magic. New York: American Book Co.

Martin, J., \& Rose, D. (2007). Working with Discourse (2nd edition). London: Continuum.

Martin, J., \& White. P. (2005). The Language of Evaluation. New York: Palgrave Macmillan.

Martin, J., Matthiessen, C. M. I. M., \& Painter, C. (1997). Working with Functional Grammar. London: Edward Arnold.

Whorf, B. L. (1956). Language Thought and Reality: Selected Writing of Benjamin Lee Whorf. In J. B, Carroll (ed.), Cambridge, MA: The MIT Press.

Yang, B-J. (2007). Realization and meaning of cline in non-finite clauses. Foreign Language Research, 3, 50-54. 